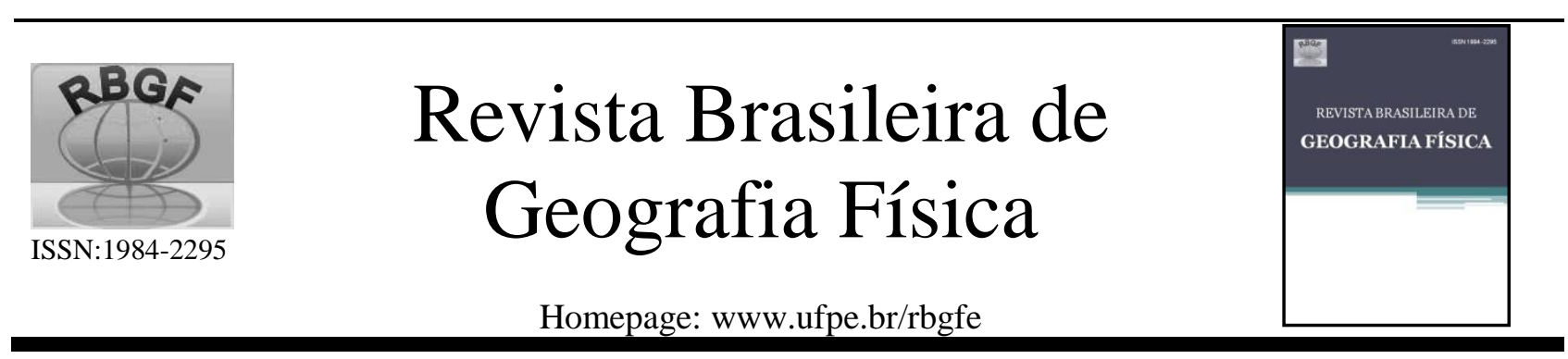

\title{
Aplicação da Análise Multivariada e da Resolução CONAMA 357/2005 para Análise da Qualidade de Água em Rios de Pernambuco
}

\author{
Nathália Bandeira Carvalho dos Santos ${ }^{1}$; Rayza Helen Graciano dos Santos ${ }^{2}$; Ronaldo Faustino da Silva ${ }^{3}$
}

${ }^{1}$ Companhia Pernambucana de Saneamento, Assistente Técnica em Saneamento (nathaliabandeiraa@gmail.com, autor correspondente); ${ }^{2}$ Universidade Federal de Pernambuco, Programa de Pós-Graduação em Ciências Biológicas (rayzahelen@hotmail.com); ${ }^{3}$ Instituto Federal de Pernambuco, Departamento Acadêmico de Infraestrutura e Construção Civil (ronaldofaus@gmail.com).

Artigo recebido em 02/03/2018 e aceito em 25/06/2018

\begin{abstract}
R E S U M O
Os rios são as principais fontes de água potável para a comunidade humana e abastecem reservatórios naturais e artificiais e a redução da disponibilidade hídrica está diretamente relacionada principalmente aos processos de urbanização. Os rios Gurjáu, Pirapama, Glória do Goitá e Capibaribe estão inseridos no estado de Pernambuco e possuem importância econômica principalmente para o consumo humano. O objetivo deste trabalho foi avaliar as variáveis físico-químicas da água pela Resolução CONAMA 357/2005 verificando os parâmetros conformes pela legislação e através da análise estatística multivariada. As coletas foram realizadas em seis pontos entre os meses de maio e junho de 2016. As análises das amostras de águas foram realizadas de acordo com os procedimentos estabelecidos no Standard Methods of Analyses for the Examination of Water and Wastewater, $22^{a}$ Edição. Com análise físico-química das amostras de água dos rios foi possível identificar que alguns parâmetros se encontram dentro dos limites permitidos pela Resolução 357/05 do CONAMA, no entanto os outros parâmetros se apresentaram com valores superiores aos permitido. As amostras RG, RP, RC-400, RGO-620 foram classificadas como classe 2 das águas doces e RC-300 E RC-950 sendo classificados como classe 1 das águas salobras (CONAMA 357/05). Com a análise multivariada o dendrograma do UPGMA, separou as amostras em dois grupos de acordo com a similaridade dos resultados das variáveis físico-químicas. A correlação cofenética das amostras exibiu que as amostras não são linearmente tão relacionadas entre si, corroborando com os resultados da matriz triangular. A análise estatística utilizada foi a Análise Principal de Componente- no Fitopac 6.1. Com a aplicação da PCA e da matriz retangular foi possível reduzir o número de indicadores de qualidade de água, selecionando os indicadores mais determinantes para as variações das características dos ambientes estudados. Os resultados obtidos permitem afirmar que a análise multivariada categorizou as amostras de águas estudadas e que os rios estudados embora apresentem algum de seus parâmetros alterados se mostram com um bom nível de potabilidade o que garante a sua utilização pela sociedade, porém se faz necessário o contínuo monitoramento das águas para verificar possíveis alterações que possam comprometer o uso da água pela população.

Palavras-chave: Análises físico-químicas, Rios de Pernambuco, Análise multivariada, Análise de Componente Principal-PCA
\end{abstract}

\section{Application of Multivariate Analysis and Resolution CONAMA 357/2005 for Analysis of Water Quality in Rivers of Pernambuco}

\begin{abstract}
A B S T R A C T
Rivers are the main sources of drinking water for the human community and supply natural and artificial reservoirs and the reduction of water availability is directly related mainly to urbanization processes. The rivers Gurjáu, Pirapama, Glória do Goitá and Capibaribe are located in the state of Pernambuco and are of economic importance mainly for human consumption. The objective of this study was to evaluate the physico-chemical variables of water by CONAMA Resolution 357/2005 verifying the parameters compliant by the legislation and through the multivariate statistical analysis. The samples were collected at six points between May and June 2016. The water samples were analyzed
\end{abstract}

Santos; N. B. C., Santos; R. H. G. Silva, R. F. 
according to the procedures established in the Standard Methods of Analysis for the Examination of Water and Wastewater, 22nd Edition. With physical-chemical analysis of the samples of water from the rivers it was possible to identify that some parameters are within the limits allowed by Resolution 357/05 of CONAMA, however the other parameters were presented with values higher than those allowed. The samples RG, RP, RC-400, RGO-620 were classified as freshwater class 2 and RC-300 E RC-950 being classified as class 1 of brackish waters (CONAMA 357/05). With the multivariate analysis the UPGMA dendrogram separated the samples into two groups according to the similarity of the results of the physicochemical variables. The co-optic correlation of the samples showed that the samples are not linearly related to each other, corroborating with the results of the triangular matrix. The statistical analysis used was the Principal Analysis of Component - in Fitopac 6.1. With the application of PCA and the rectangular matrix it was possible to reduce the number of water quality indicators, selecting the most determinant indicators for the variations of the characteristics of the studied environments. The results obtained allow to affirm that the multivariate analysis categorized the samples of studied waters and that the studied rivers although they present some of their altered parameters show with a good level of potability that guarantees their use by the society, however it is necessary the continuous water monitoring to verify possible alterations that could compromise the use of water by the population.

Keywords: Physico-chemical analysis, Pernambuco Rivers, Multivariate analysis, Principal Component Analysis-PCA

\section{Introdução}

A qualidade das águas é caracterizada por parâmetros físicos, químicos e microbiológicos, os quais são submetidos constantemente a interferências de ordem natural, do próprio ecossistema, e de ordem antrópica, advindas das atividades de uso e ocupação do solo (Medeiros et al., 2016).

A água é um dos recursos naturais de maior importância para o planeta, sendo o principal constituinte dos organismos vivos. Ela é imprescindível para a qualidade de vida e o desenvolvimento econômico de uma população, além de ser componente da paisagem e do meio ambiente. A água doce, em especial, é um recurso natural finito, cuja qualidade vem sendo perdida devido ao mau uso, ex. contaminação, e aproveitamento indevido pela população (Ferreira e Ferreira, 2006).

O estado de Pernambuco é privilegiado pela quantidade de estuários que possui, porém, porém resultados das variáveis dos rios mostram que as ações antrópicas estão gradativamente diminuindo a qualidade da água dos mesmos (CPRH, 2013).

O comprometimento da qualidade da água ocorre devido à poluição causada por diferentes fontes, nos quais podem ser efluentes domésticos, industriais e deflúvio superficial urbano e agrícola (Merten e Minella, 2002). A alta concentração humana mal planejada faz com que essas regiões sejam intensamente impactadas por efluentes domésticos e industriais e pela destruição das áreas verdes contíguas, motivada pela exploração imobiliária desordenada (Teixeira et al., 2015).

Os parâmetros biológicos, físicos e químicos, determinam as características de potabilidade necessárias para que, a água chegue até a população de uma maneira mais segura e confiável a fim de que, possa ser utilizada no consumo humano. Esses parâmetros são regulamentados por normas e/ou padrões definidos em portarias do ministério da saúde. (Richter e Netto, 1999).

A análise estatística multivariada tem sido empregada em diferentes áreas do conhecimento. Em recursos hídricos, Ceballos (1995), Silva (1997), Aguilera et al. (2001), Brito (2003), entre outros, utilizaram-nas para avaliar impactos ambientais e/ou identificar variáveis de maior significância no conjunto das variáveis que definem a qualidade das águas

A análise fatorial em componentes principais é um procedimento estatístico, cujo principal objetivo é ordenar e reduzir o número de variáveis em subgrupos menores, correlacionadas entre si, denominados de fatores ou componentes principais, de forma a explicar a maior variabilidade possível do conjunto de dados (Andrade, 1989). Por meio dos fatores principais, é possível selecionar aquelas variáveis de maior participação em cada fator e definir as que deverão ser monitoradas, reduzindo-se, assim, os custos com análises de variáveis de menor importância na qualidade das águas (Brito, 2006).

Os rios Gurjaú, Pirapama, Glória do Goitá e Capibaribe estão inseridos no estado de Pernambuco, tendo o último destaque devido a sua extensão no estado pernambucano, porém em contrapartida o mesmo também é considerado o sétimo rio mais poluído do Brasil, devido principalmente ao lançamento de esgotos domésticos in natura (Santiago et al., 2010). Esses rios são importantes para a economia local uma vez que abastecem reservatórios de água naturais e artificiais, como também fornecem água para irrigação para agricultura, criação de animais e abastecem as populações ribeirinhas como fonte de alimento e renda (Barros, 2009). 
Uma vez que esses rios estão passando por um alto processo de intervenção antrópica é indispensável que seja feita regularmente análises físico-químicas da água, para mensurarmos os quão esses impactos estão modificando o ecossistema aquático. Através dessas análises podemos identificar e avaliarmos as condições que se encontram os mananciais e quais as variáveis encontradas que mais influenciam para a qualidade da água. De acordo com contexto descrito, o objetivo do trabalho foi avaliar a qualidade da água dos rios Gurjaú, Pirapama, Glória do Goitá e Capibaribe e observar quais variáveis mais afetam a sua potabilidade fazendo uso da análise físicoquímica e a análise estatística multivariada e pela resolução CONAMA 357/2005 visando subsidiar medidas de monitoramento e gestão da qualidade das águas dos rios.

\section{Material e métodos}

\section{Descrição das áreas de estudo}

Rio Gurjaú - Está inserido na Unidade de Conservação Estadual Refúgio de Vida Silvestre (RVS) Matas do Sistema Gurjaú $\left(08^{\circ} 10^{\prime} 00^{\prime \prime} \mathrm{S}\right.$ e $\left.35^{\circ} 02^{\prime} 30^{\prime \prime} \mathrm{W}\right)$, localizada entre os municípios de Cabo de Santo Agostinho, Jaboatão dos Guararapes e Moreno, pertencentes à Região Metropolitana do Recife (RMR), no Estado de Pernambuco.

A RVS é um importante remanescente de Floresta Atlântica Nordestina, possuindo grande diversidade biológica constituída por diferentes grupos de plantas e animais, com a presença de espécies endêmicas e ameaçadas (Tabarelli et al., 2006).

Rio Pirapama - Está inserido no estado de Pernambuco, tendo a sua nascente no município de Pombos e percorre $80 \mathrm{~km}$ até a sua foz que está localizada no município do Cabo de Santo Agostinho. A bacia do rio Pirapama é composta por doze sub-bacias e ocupa parte dos municípios de Jaboatão dos Guararapes, Cabo de Santo Agostinho, Ipojuca, Moreno, Escada, Vitória de Santo Antão e Pombos, sendo, os quatros primeiros inseridos na Região Metropolitana do Recife (CPRH, 2013).

Rio Glória do Goitá - A área de estudo corresponde à bacia hidrográfica do rio Goitá, sendo esta uma sub-bacia do rio Capibaribe localizada na mesorregião da mata pernambucana a sub-bacia do rio Goitá é um importante tributário do município de Gloria do Goitá no estado de Pernambuco (Melo et al., 2011).

Rio Capibaribe - $\mathrm{O}$ rio Capibaribe é considerado um dos principais recursos fluviais do estado de Pernambuco, devido sua extensão e sua historicidade para o Brasil e especial para o Recife. (Noriega, 2010). Inserido nas mesorregiões Metropolitana do Recife, na Mata Pernambucana e no Agreste Pernambucano a bacia hidrográfica do rio Capibaribe possui uma área de $8.827,6 \mathrm{~km}^{2} \mathrm{e}$ ocupa cerca de 9,0\% do Estado. Na mesorregião Metropolitana do Recife (RMR) possui uma área de $2.785,4 \mathrm{~km}^{2}$, o equivalente a $2,8 \%$ do território pernambucano. Nesta mesma mesorregião o Capibaribe contempla 04 microrregiões, 14 municípios e o distrito estadual de Fernando de Noronha (Andrade, 2009).

\section{Coleta das águas}

Foram determinados seis pontos de coletas para a análise das variáveis físico-químicas dos rios. As amostragens das águas dos rios: Gurjaú, Pirapama, Glória do Goitá e Capibaribe (Figura 1) se deram entre os meses de maio e junho de 2016.

O local escolhido para a coleta da água no rio Gurjaú ( $08^{\circ} 10^{\prime} 00^{\prime \prime}$ S e $\left.35^{\circ} 02^{\prime} 30^{\prime \prime} \mathrm{W}\right)$, denominado na análise como RG, foi à montante da barragem de Gurjaú na RVS Gurjaú, local este que possui uma estação de tratamento de água (ETA) Gurjaú e é utilizado pela Companhia Pernambucana de Saneamento (COMPESA) para abastecimento de água da população dos municípios de Cabo de Santo Agostinho, Jaboatão dos Guararapes e Recife.

O local para a coleta da água do rio Pirapama, denominado na análise como RP, foi a montante da barragem de Pirapama ( $8^{\circ} 17^{\prime} 19^{\prime \prime} \mathrm{S}$ e $35^{\circ} 4^{\prime} 16^{\prime \prime}$ O) que também é utilizado pela COMPESA para abastecimento de água da população na Região metropolitana do Recife (RMR).

Para o estudo da qualidade da água do rio Capibaribe foi escolhido três locais de amostragem no baixo do Capibaribe. O primeiro ponto de coleta denominado como, RC-300, está localizado à jusante da Usina Petribú, na divisa dos municípios de Carpina e Lagoa de Itaenga ( $7^{\circ} 53^{\prime} 19.24951^{\prime \prime} \mathrm{S}$ $35^{\circ} 14^{\prime} 22.83701 " \mathrm{~W}$ ), o segundo local, RC- 400, está localizado à jusante da cidade de Paudalho, na ponte da BR-408, no município de Paudalho ( $7^{\circ} 53^{\prime}$ 41.6778" S $\left.35^{\circ} 10^{\prime} 26.99707^{\prime \prime} \mathrm{W}\right)$ e o último trecho, RC-950, localizado na Av. Beira Rio, na cidade do Recife (8 3' 45.64174" S 34 54' 6.28723" W) próximo ao estádio do Sport Clube do Recife.

Foi realizada coleta da água no rio glória do Goitá, sendo denominado RGO-620, na divisa dos 
municípios de São Lourenço da Mata e Paudalho

(7 $\left.57^{\prime} 55.90985^{\prime \prime} \mathrm{S} 35^{\circ} 5^{\prime} 32.4852 " \mathrm{~W}\right)$.

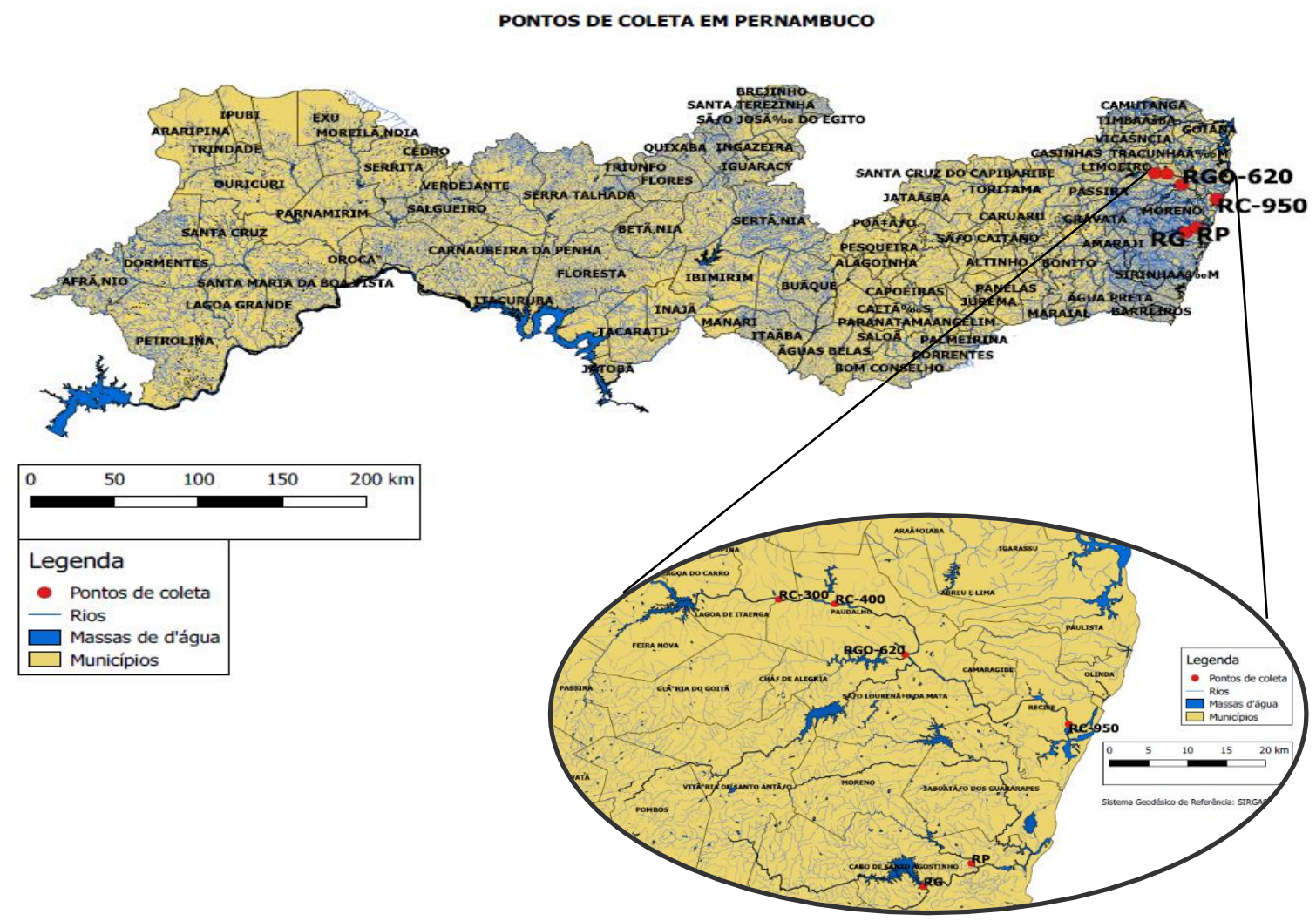

Figura 1: Localização aeroespacial dos pontos de coleta das amostras de água dos rios em Pernambuco.

\section{Análises das águas coletadas}

As análises físico-químicas e biológicas das águas foram realizadas na Companhia Pernambucana de Saneamento (COMPESA), Agência Estadual de Meio Ambiente (CPRH) e na Lógica Ambiental LTDA.

Para este estudo foram utilizadas as seguintes análises: turbidez, $\mathrm{pH}$, cor, demanda bioquímica por oxigênio (DBO), oxigênio dissolvido (OD), nitrato, nitrogênio amoniacal, fósforo total, temperatura e condutividade.

As análises físico-químicas das águas os reagentes foram preparados conforme a Standard Methods of Analyses for the Examination of Water and Wastewater, 22 ${ }^{a}$ Edição (2012), (Silva et al., 2012).

\section{Análises estatísticas}

Atualmente, as técnicas de análise multivariada são populares porque permitem observar através dos descritores e das amostras a situação desse conjunto de dados e assim poder determinar quais medidas utilizar para melhorar as situações de tais investigações. A análise multivariada refere-se a todas as técnicas estatísticas que simultaneamente analisam múltiplas medidas sobre os objetos ou indivíduos sob verificação (Junior et al., 2009).

As análises foram realizadas nos softwares Fitopac 2.1 e Pcord 4. Os dados obtidos foram tabulados em uma matriz principal de acordo com o número de amostras e de descritores.

Para a PCA foi utilizada a matriz no Fitopac2.1 software, onde foram observados os índices de correlação das variáveis com os eixos, o percentual do valor acumulado nos três primeiros eixos e o percentual de variação esperada, o que corresponde ao modelo de vara quebrada.

\section{Resultados e discussão \\ Análise físico-química}

A água destinada ao consumo humano tem prioridade aos demais usos e como não se encontra água pura na natureza, esta deve passar por um conjunto de etapas denominado tratamento de água 
afim de que possa ser utilizada pelo homem, sem que lhe represente risco à saúde. Este é feito nas estações de tratamento de água (ETA) (Philippi e Pelicioni, 2005).

As águas superficiais, subterrâneas e potáveis, no Brasil, são estudadas a partir de legislações. O Conselho Nacional de Meio Ambiente (CONAMA) dispõe de resoluções que estabelecem o enquadramento das águas brutas, tanto para as águas superficiais, quanto para as águas subterrâneas. A Resolução CONAMA N³57/2005 fala sobre a classificação dos corpos de água e diretrizes ambientais para o seu enquadramento, bem como estabelece as condições e padrões de lançamento de efluentes, e dá outras providências. Em todos os casos, os enquadramentos são feitos a partir de parâmetros estabelecidos a partir dos seus usos (Lordelo et al., 2016).

De acordo com o CONAMA 357/2005 os rios no Brasil são classificados de acordo com o grau de salinidade, podendo ser classificados como: água doce, salobra e salina e de acordo com os seus usos múltiplos da água, podendo ser classificado como classe 1, 2 e 3 . Em sua grande maioria os rios de Pernambuco são classificados como classe 2 das águas doces, porém devido a presença de fatores abióticos e bióticos que influenciam no grau de salinidade e condutividade dos cursos hídricos são classificados como classe 1 das águas salobras (CPRH, 2013).

De acordo com o valor da variável condutividade apresentado (Fig. 12), as amostras de águas RG, RP, RC-400, RGO-620 serão avaliados de acordo com o CONAMA 357/2005, como classe 2 das águas doces e as amostras RC300 e RC-950 como classe 1 das águas salobras.

$\mathrm{O}$ pH, potencial hidrogeniônico é medido pela quantidade de prótons de $\mathrm{H}+$, e representa a concentração ácida ou alcalina do ambiente aquático. De acordo com a figura 12, observamos que as águas dos rios estão dentro do valor permitido pelo CONAMA 357/2005, onde é permitido que as águas doces classe 1 e 2 tenham um $\mathrm{pH}$ entre 6,0 a 9,0 e as águas salobras classe 1 pH entre 6,5 a 8,5 (Fig. 2).

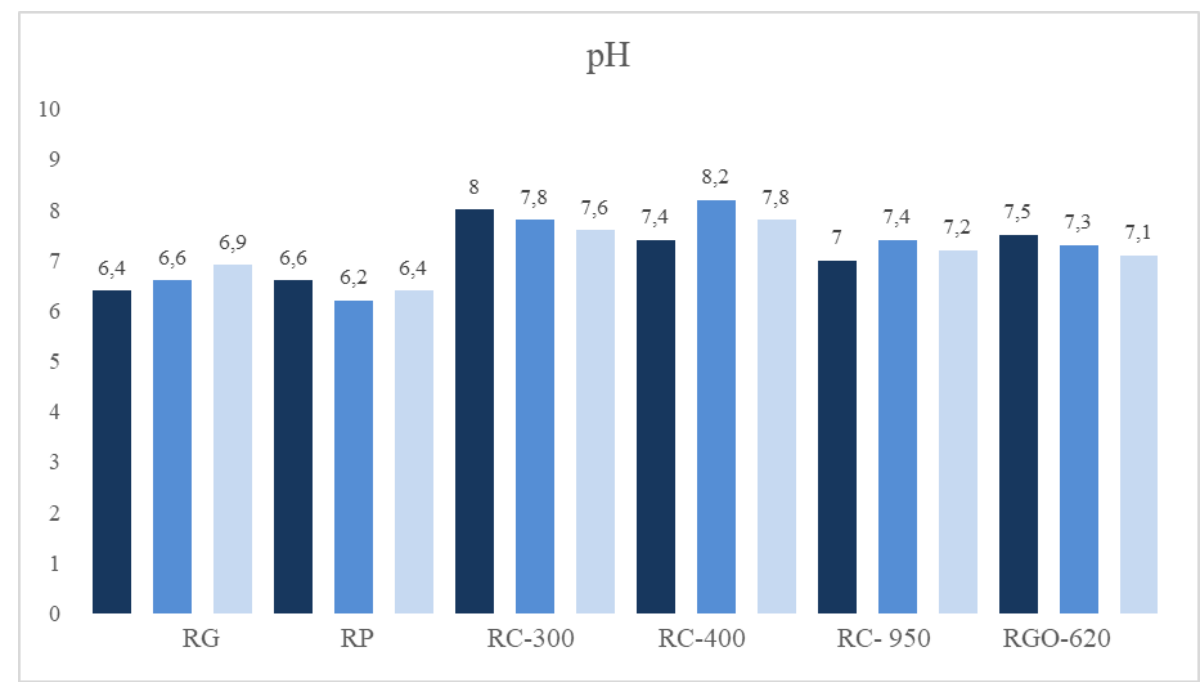

Figura 2: Variação do pH das amostras de água coletadas.

A condutividade é uma medida da capacidade de conduzir a corrente elétrica devido aos cátions e aos ânions presentes na água, devido a dissociação de outras substâncias. A condutividade da água é um parâmetro importante para águas com finalidade para o abastecimento humano (Esteves, 2011). De acordo com Agência Nacional das Águas (ANA) a condutividade elétrica de águas doce, deve ser inferior a $500 \mu \mathrm{S} / \mathrm{cm}$, valores superiores a estes podem indicar problemas de poluição. Podemos observar na figura 12, que os rios que se encontram dentro do valor permitido pela ANA é o rio Gurjaú (RG) e rio Pirapama.

As amostras dos rios RC-300 e RC-950 apresentaram a condutividade muito maior do que a esperada para as águas doce classe 2, estando, portanto, enquadrados em aguas salobras classe $1 \mathrm{e}$ apresentado risco de salinidade do solo de alto $\left(1500\right.$ a $3000 \& S / c m$ a $\left.25^{\circ} \mathrm{C}\right)$ a muito alto (>3000 $\& \mathrm{~S} / \mathrm{cm}$ a $25^{\circ} \mathrm{C}$ ) segundo a Agência Estadual do Meio Ambiente (CPRH) (Fig. 3). Este valor superior apresentado pode ser um índice de poluição no local onde foi coletada as amostras de 
água. No CONAMA 357/2005 não possui valores

para o parâmetro condutividade.

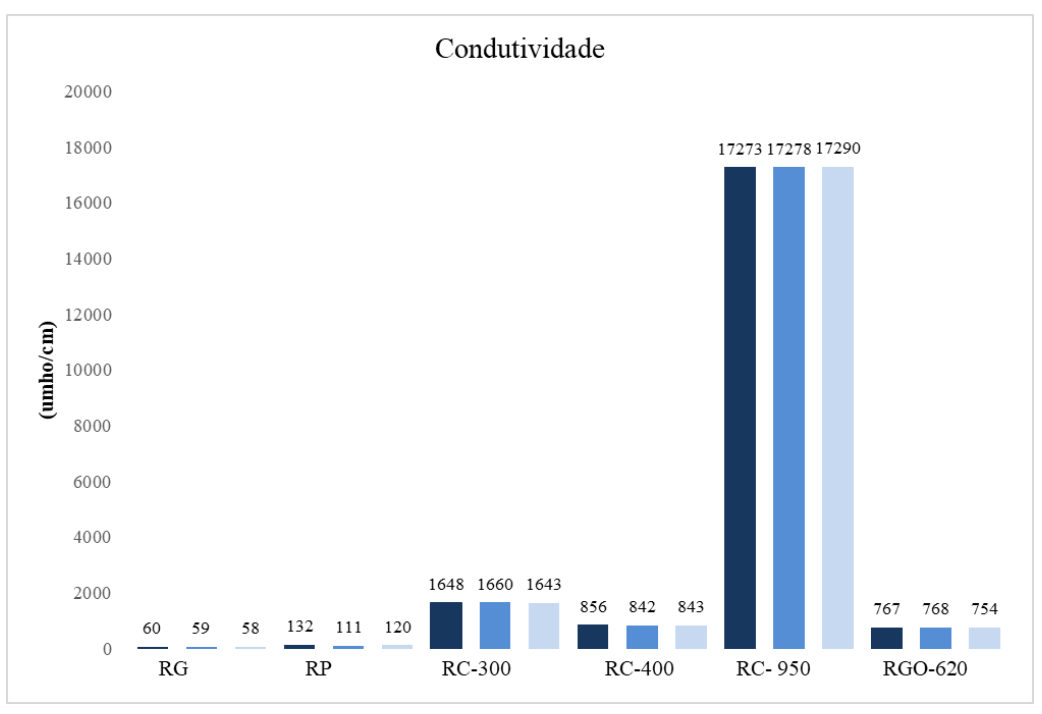

Figura 3: Variação da condutividade das amostras de água coletadas.

A Resolução CONAMA n $357 / 05$, estabelece para águas doces classe 2 e para águas salobras classe 1 , que os valores de oxigênio dissolvido devem ser inferiores a $5 \mathrm{mg} / \mathrm{L} \mathrm{O}_{2}$ (Fig. 4). Podemos observar na figura 12 , que os rios que apresentam valores superiores ao determinado pelo CONAMA são os rios Gurjaú (RG) e o rio Capibaribe-300 (RC-300).

De acordo com o CPRH (2013), os baixos valores de OD são resultantes do lançamento de efluentes domésticos, industriais e resíduos agroindustriais, principalmente no baixo rio Capibaribe, onde se encontram os piores efeitos causados pela urbanização.

A entrada de esgotos no estuário pode aumentar a Demanda Bioquímica por Oxigênio (DBO) e Demanda Química por Oxigênio (DQO), tendo como consequência a eutrofização e o favorecimento da condição anóxica (diminuição de oxigênio) deste ambiente (Nóbrega, 2011).

A DBO normalmente é considerada como a quantidade de oxigênio consumido durante um período de tempo de 5 dias numa temperatura de incubação de $20^{\circ} \mathrm{C}$, sendo por isso referido como $\mathrm{DBO}_{5,20}$. Na análise físico-química, as amostras de água de RG, RP, RC-300 e RC-400 se enquadram dento do valor permitido pelo CONAMA para águas doces classes 2 que é de $5 \mathrm{mg} / \mathrm{L} \mathrm{O}_{2}$ (Fig. 5). Já as amostras de RC-950 e RGO-620 se encontram acima da normalidade para águas doces de classe 2 (até $5 \mathrm{mg} \mathrm{L}-1 \mathrm{O}_{2}$ ), atingindo um valor máximo de $28,9 \pm 1,5 \mathrm{mg} \mathrm{L} \mathrm{O}_{2}$ no rio Capibaribe-950 (Tabela $1)$.

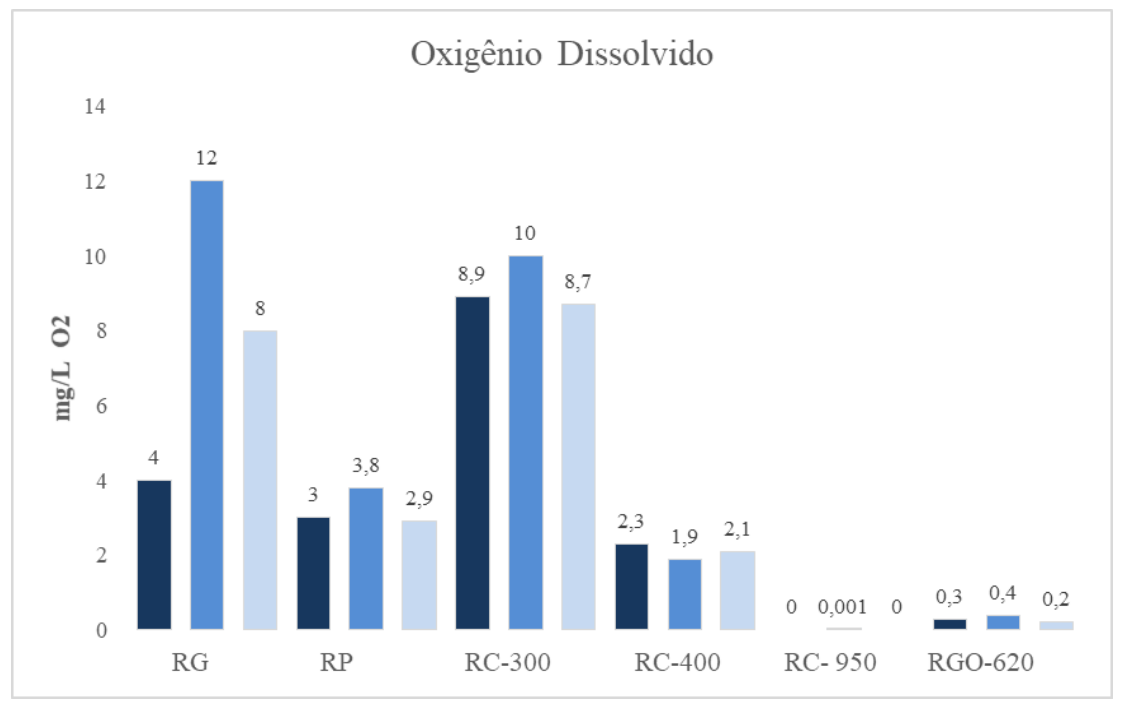

Figura 4: Variação do nível de OD das amostras de água coletadas. 


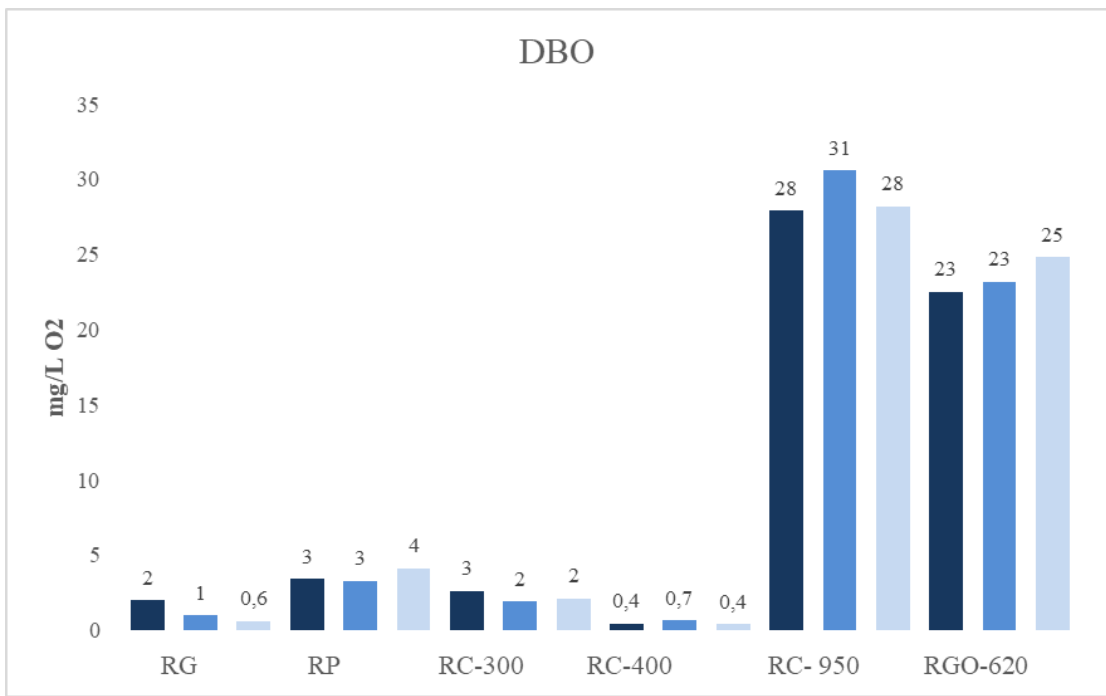

Figura 5: Variação do nível da DBO das amostras de água coletadas.

A turbidez da água pode ser definida como a presença de materiais sólidos em suspensão, que reduzem a sua transparência. A diminuição da nitidez pode ser provocada por diversos fatores abióticos e bióticos, como: presença de algas, plâncton, matéria orgânica e muitas outras substâncias como o zinco, ferro, manganês e areia, resultantes (Donadio et al., 2005).
Os valores permitidos para turbidez segundo os padrões do CONAMA 357/2005 para águas doces classe 2, deve estar abaixo de 100 UNT (Fig. 6), como mostra na Tabela 1 , todos os rios se encontram dentro do valor permitido. Diante disto podemos inferir que as amostras de águas coletadas possuem baixa concentração de sólidos em suspensão e pequena quantidade de matéria orgânica e com isso garantindo a potabilidade da água para consumo humano.

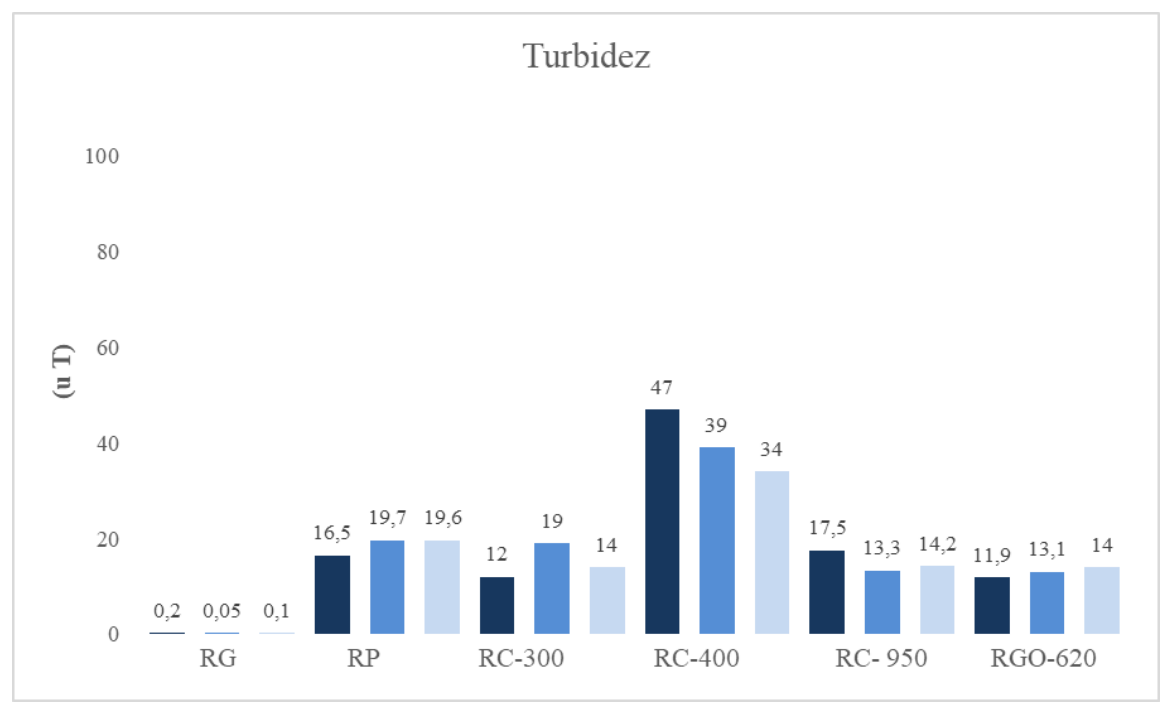

Figura 6: Variação do nível de turbidez das amostras de água coletadas.

A cor da água surge, em geral a partir da presença de matéria orgânica e/ou inorgânica, substâncias húmicas, taninos, mas também por substâncias metálicas como o ferro, manganês e por resíduos industriais fortemente coloridos (Cornationi, 2010).
Para o parâmetro cor, as águas doces (classe 2) devem conter uma quantidade menor ou igual de $75 \mathrm{Pt} / \mathrm{Co}$, no entanto, para as águas salobras classe 1 , substâncias que produzem cor, odor e turbidez estão virtualmente ausentes segundo o CONAMA (Fig. 7). Das amostras dos rios analisadas os que se enquadraram dentro do valor permitido foram: RC- 
300, RC-950 e RGO-620, obtendo valores superiores ao permitido para água doce classe 2 : RG, RP e RC-400 (Tabela 1).

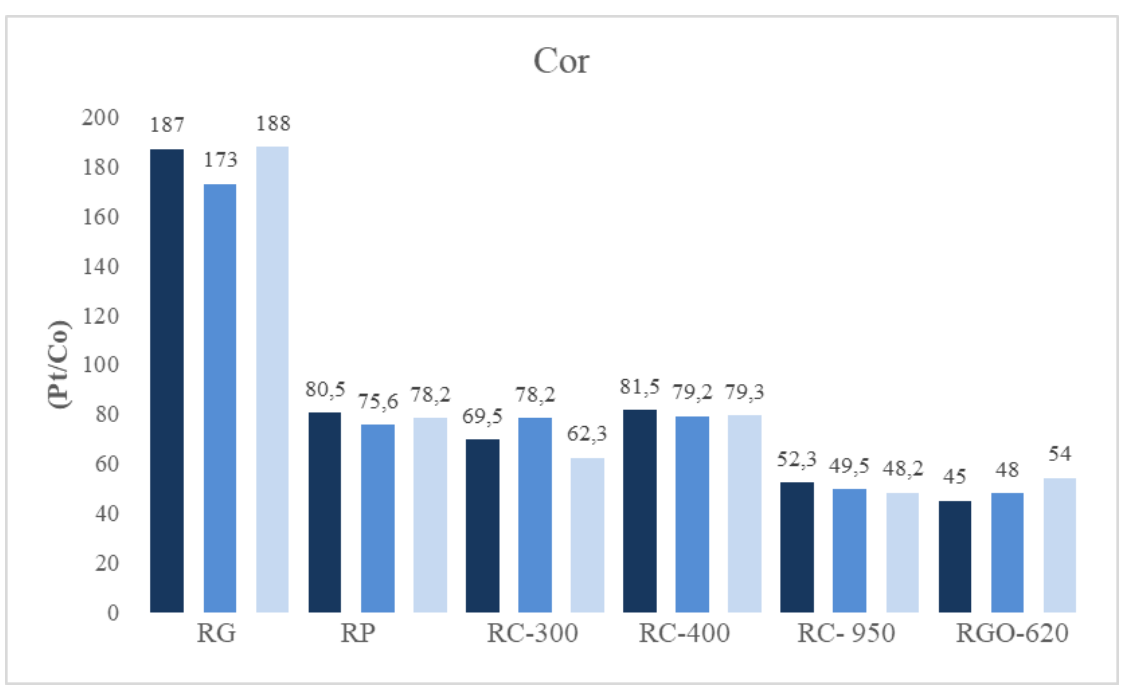

Figura 7: Variação do nível de cor das amostras de água coletadas.

A presença de altas concentrações de amônio em águas superficiais pode indicar contaminação por esgoto bruto, efluentes industriais, ou devido a fertilizantes (Parron et al., 2011). De acordo com o CONAMA 357/05, a concentração de nitrogênio amoniacal presente em águas doce classe 2 , varia de acordo com o pH da amostra de água (Tabela 1). Sendo de:

$$
3,7 \mathrm{mg} / \mathrm{L} \mathrm{N} \text {, para } \mathrm{pH} \leq 7,5
$$$$
2,0 \mathrm{mg} / \mathrm{L} \mathrm{N} \text {, para } 7,5<\mathrm{pH} \leq 8,0
$$$$
1,0 \mathrm{mg} / \mathrm{L} \mathrm{N} \text {, para } 8,0<\mathrm{pH} \leq 8,5
$$

$0,5 \mathrm{mg} / \mathrm{L} \mathrm{N}$, para $\mathrm{pH}>8,5$
Para águas salobras classe 1 , a concentração de nitrogênio amoniacal permitida é de $0,40 \mathrm{mg} / \mathrm{L}$ $\mathrm{N}$. Dentre as águas dos rios analisadas o RG, RC300 e RC-400 obtiveram valores inferiores a 0,5 $\mathrm{mg} / \mathrm{L}$ de $\mathrm{N}$ (sendo RC-300 classificada como salobra classe 1) e o RC-950 com um valor de 1,87, no entanto os valores correspondentes aos de $\mathrm{pH}$ não são compatíveis, uma vez que todas as amostras obtiveram valores de $\mathrm{pH}$ menor que 7,5 (Tabela 1).

As amostras de RP e RGO-620 apresentaram com valores de nitrogênio amoniacal alterado e superior a variação permitida pelo CONAMA (Fig. 8 ), o que pode indicar a grande atividade humana $\mathrm{e}$ a possível contaminação por esgoto ou efluentes.

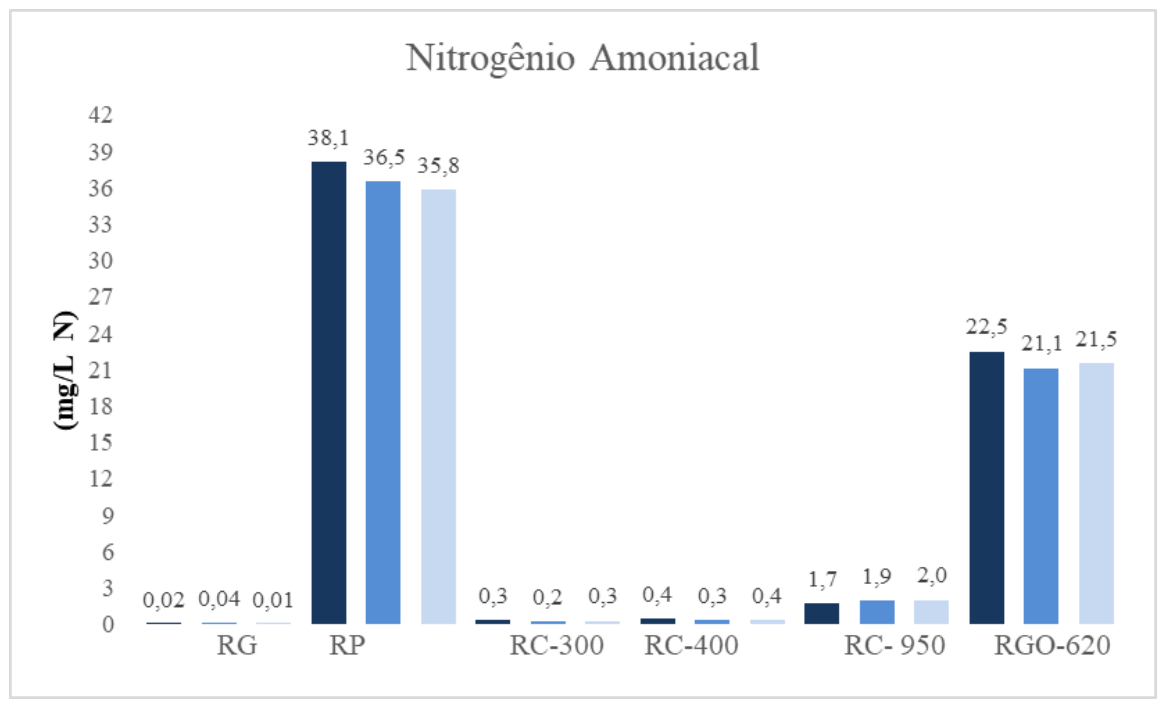

Figura 8: Variação da concentração de nitrogênio amoniacal das amostras de água coletadas. 
O nitrato geralmente comumente está presente em pequenas concentrações em águas superficiais, no entanto, podem atingir elevadas concentrações em algumas águas subterrâneas (até $5 \mathrm{mg} \mathrm{L}^{-1}$ ). A água potável não deve ter mais do que $10 \mathrm{mg} \mathrm{L}^{-1} \mathrm{de}$
$\mathrm{NO}_{3}^{-}$(Brasil, 2005). Segundo o CONAMA, o valor permitido de nitrato é de $10,0 \mathrm{mg} / \mathrm{L} \mathrm{N}$ (água doce) e podemos observar que as amostras de água dos rios apresentaram valores inferiores ao permitido (Fig. 9 e Tabela 1).

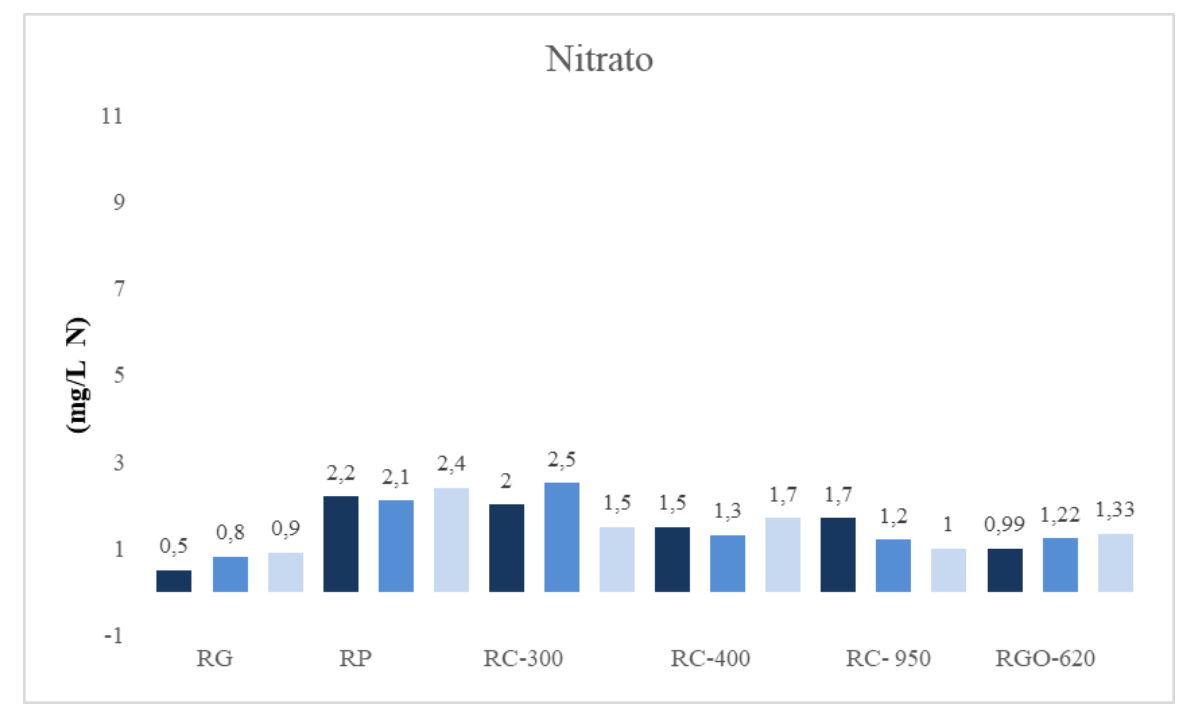

Figura 9: Variação da concentração de nitrato das amostras de água coletadas.

Segundo o CONAMA 357/2005 para os rios classe 2, os mesmos devem estar enquadrados nesses padrões: lêntico $\leq 0,030 \mathrm{mg} / \mathrm{L}$; intermediário e tributário de lêntico $\leq 0,050 \mathrm{mg} / \mathrm{L}$; lótico e tributário de intermediário $\leq 0,10 \mathrm{mg} / \mathrm{L}$. E para os rios água salobra classe 1 a concentração de fosfato permitida é de $0,124 \mathrm{mg} / \mathrm{L} \mathrm{P}$. Com isso o RG se classifica como lêntico e o RP, RC-300, RC-400, RC-950 e RGO-620 apresentaram alta concentração de fosfato total, não se encaixando em nenhum dos padrões estabelecidos (Fig. $10 \mathrm{e}$ Tabela 1). As altas concentrações de fosfatos em corpos hídricos podem estimular o crescimento de micro e macro organismos aquáticos fotossintéticos em grandes quantidades, que por sua vez, pode desencadear processos de eutrofização (Parron et al., 2011).

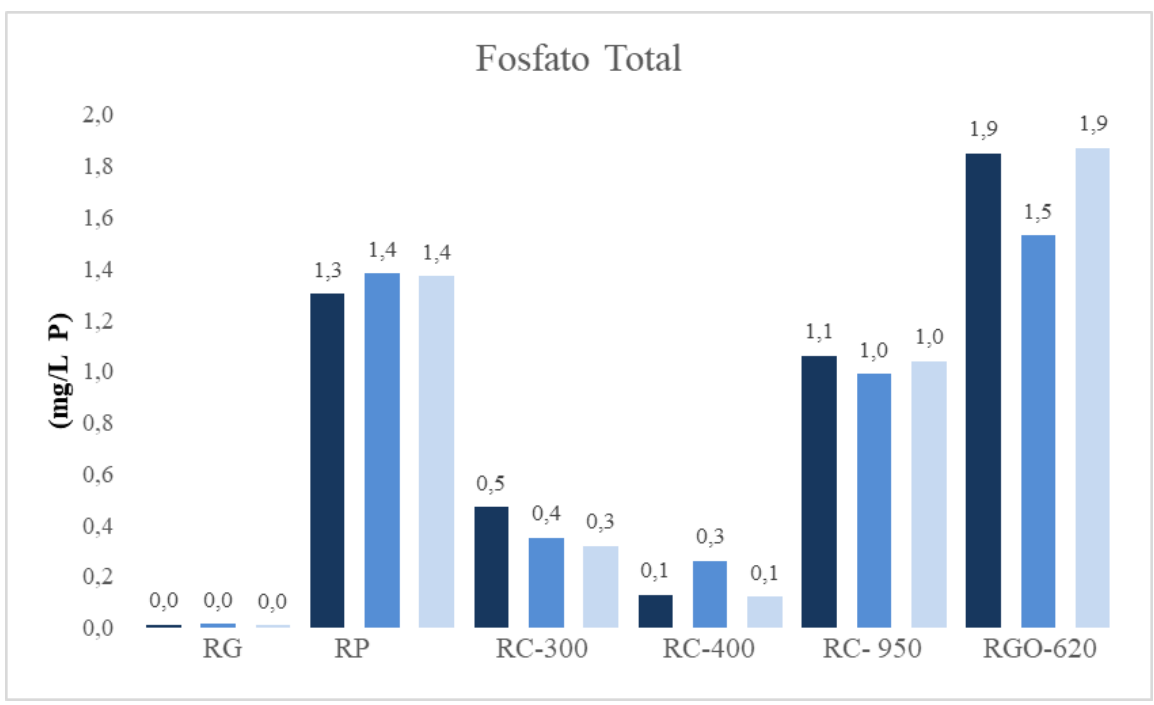

Figura 10: Variação da concentração de fosfato total das amostras de água coletadas. 
A temperatura do meio aquático está diretamente relacionada com a penetração luminosa que, juntamente com os diferentes comprimentos de ondas, é responsável pelo balanço térmico da água (Schäfer, 1985). Não existe valor estabelecido pelo CONAMA para este parâmetro, no entanto, nota-se uma maior temperatura na amostra de água do RGO-620, RC300 e RC-950 (Fig. 11 e Tabela 1), que pode ser justificada pelo ambiente onde esse rio se encontra, a influência dos fatores urbanos e provavelmente a inexistência de uma mata ciliar.

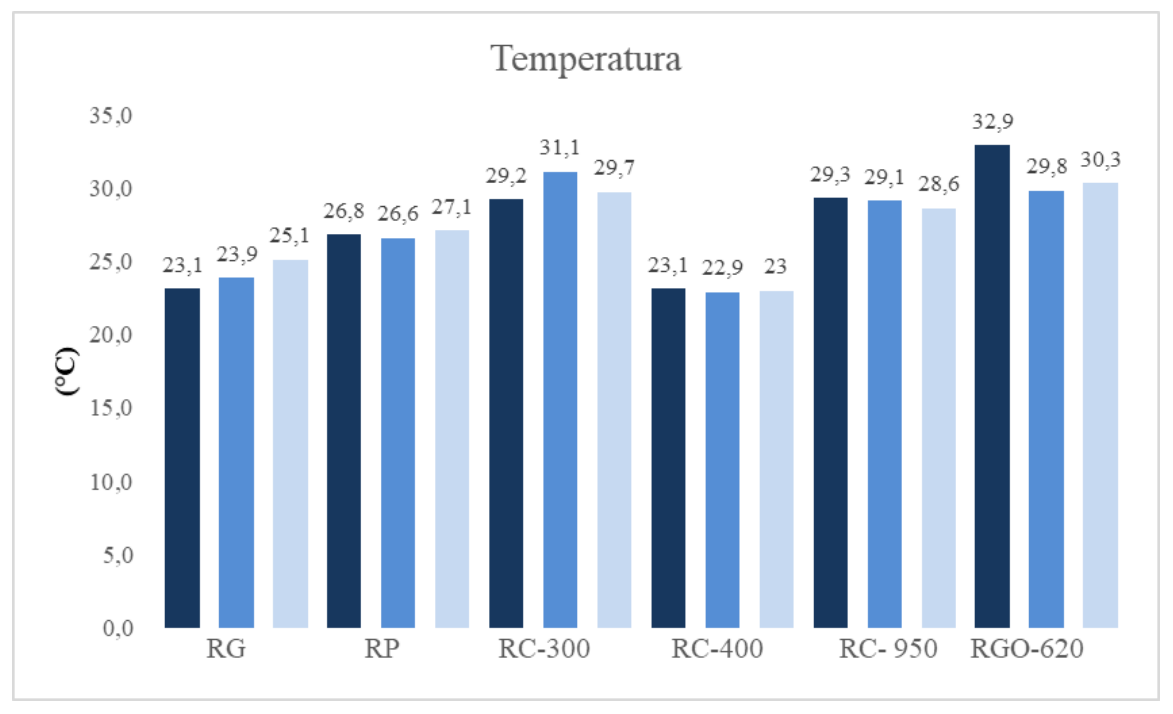

Figura 11: Variação da temperatura das amostras de água coletadas.

Tabela 1: Resultado da análise físico-química da água dos rios pernambucanos. Sendo: OD: Oxigênio Dissolvido, DBO: Demanda Bioquímica por Oxigênio.

\begin{tabular}{|c|c|c|c|c|c|c|c|c|c|c|}
\hline & $\mathrm{pH}$ & $\begin{array}{c}\text { Condutivid ade } \\
\text { (umho/sm) }\end{array}$ & $\begin{array}{c}\mathrm{OD} \\
\mathrm{mg} / \mathrm{L} \mathrm{O}_{2}\end{array}$ & $\begin{array}{c}\mathrm{DBO} \\
\mathrm{mgL} \mathrm{O}_{2}\end{array}$ & $\begin{array}{c}\text { Turbidez } \\
(\mathrm{u} \mathrm{T})\end{array}$ & $\begin{array}{l}\text { Cor } \\
\left(\mathrm{Pt} / \mathrm{C}_{0}\right)\end{array}$ & $\begin{array}{c}\text { Nitrogênio } \\
\text { Amoniacal (mg/L N) }\end{array}$ & $\begin{array}{l}\text { Nitrato } \\
(\mathbf{m g} \mathrm{L} N)\end{array}$ & $\begin{array}{c}\text { Fos fato Total } \\
\text { (mg/L P) }\end{array}$ & $\begin{array}{c}\text { Temperatura } \\
\left({ }^{\circ} \mathrm{C}\right) \\
\end{array}$ \\
\hline RG & $6,6 \pm 0,3$ & $59 \pm 1,1$ & $8 \pm 4$ & $1,2 \pm 0,7$ & $0,1 \pm 0,1$ & $183 \pm 8,4$ & $0,02 \pm 0,02$ & $0,7 \pm 0,2$ & $0,012 \pm 0,003$ & $24 \pm 1,01$ \\
\hline $\mathbf{R P}$ & $6,4 \pm 0,2$ & $121,2 \pm 10,1$ & $32 \pm 0,5$ & $3,6 \pm 0,4$ & $18,6 \pm 1,8$ & $78,1 \pm 2,4$ & $36,8 \pm 1,2$ & $2,2 \pm 0,1$ & $1,35 \pm 0,04$ & $26,8 \pm 0,2$ \\
\hline RC-300 & $7,8 \pm 0,2$ & $1650 \pm 8,7$ & $9,2 \pm 0,7$ & $2,2 \pm 0,4$ & $15 \pm 3,6$ & $70 \pm 7,96$ & $0,27 \pm 0,04$ & $2 \pm 0,5$ & $0,38 \pm 0,08$ & $30 \pm 0,98$ \\
\hline RC-400 & $7,8 \pm 0,4$ & $847 \pm 7,81$ & $2,1 \pm 0,2$ & $0,5 \pm 0,14$ & $40 \pm 6,6$ & $80 \pm 1,3$ & $0,37 \pm 0,06$ & $1,5 \pm 0,2$ & $0,17 \pm 0,08$ & $23 \pm 0,1$ \\
\hline RC-950 & $72=0,2$ & $17280 \pm 8,7$ & 0 & $28,9 \pm 1,5$ & $15 \pm 2,2$ & $50 \pm 2,1$ & $1,87 \pm 0,13$ & $1,3 \pm 0,36$ & $1,03 \pm 0,04$ & $29 \pm 0,36$ \\
\hline RGO-620 & $7,3 \pm 0,2$ & $763 \pm 7,8$ & $0,3 \pm 0,1$ & $23,5 \pm 1,2$ & $13 \pm 1,05$ & $49 \pm 4,6$ & $21,7 \pm 0,7$ & $1,18 \pm 0,17$ & $1,75 \pm 1,19$ & $31 \pm 1,66$ \\
\hline
\end{tabular}

\section{Análise estatística}

No Pcord foi analisado o teste estatístico DCA, para observar o coeficiente de comprimento dos dados, apresentando um valor de 1.295 , indicando qual análise mais adequada a ser utilizada no Fitopac.

De acordo com o valor apresentado a melhor análise estatística é a PCA com correlação, assim corroborando com o que foi discutido por Manly (2008) que afirma como os dados são lineares e que sendo o coeficiente menor que 2 a literatura define que a melhor análise é a PCA pois reduz a quantidade de variáveis ambientais e mede a força das variáveis sobre as unidades amostrais linearmente.

O dendrograma do UPGMA, (Fig. 12), separou as amostras em dois grupos de acordo com a similaridade dos resultados das variáveis físicoquímicas, sendo: RG, RC 300 e RC 400 e RP, RC950 com RG-620, mostrando que os descritores utilizados para a multivariada conseguiram separar grupos. $\mathrm{O}$ agrupamento aglomerado que

Santos; N. B. C., Santos; R. H. G. Silva, R. F. 
apresentou a melhor correlação cofenética no FitoPac foi o UPGMA (Fig. 13), com o valor de aproximadamente 0,76 .

Podemos observar que a amostra RG ficou no mesmo grupo que o RC-300 e RC-400, porém os últimos sendo os mais similares. $\mathrm{O}$ outro grupamento formado foi entre as amostras RP, RC950 e RGO-620, sendo as últimas amostras as que possuem os resultados mais similares.

A técnica de agrupamento interliga as amostras por suas associações, produzindo um dendrograma onde as amostras semelhantes, segundo as variáveis escolhidas, são agrupadas entre si, sendo que quanto menor a distância entre os pontos, maior a semelhança entre as mesmas (Moita Neto e Moita, 1998).

Nota-se que as amostras coletadas no rio Capibaribe (RC-300 e RC-400) mostram-se mais similaridade em sua composição físico-química (Fig. 13). No entanto, a amostra RC-950 também do rio Capibaribe mostrou-se mais distinta, o que pode ser explicado pela distância entre as amostras coletadas do mesmo rio, uma vez que, a última se encontra na Região Metropolitana do Recife e que a qualidade da água pode estar sendo influenciada pela urbanização e poluição da região.

O rio Glória do Goitá (RGO-620), mesmo sendo um afluente do rio Capibaribe, também se apresenta agrupado distante de seu afluente, apresentando grandes diferenças no que diz respeito a sua composição físico-química.

Diante disto, podemos constatar que a distância entre as amostras dos rios coletadas surte efeitos nos resultados do agrupamento. Um exemplo característico disso neste estudo são os resultados das amostras do rio Capibaribe, onde, as amostras RC-950 e RGO-620 (afluente desse rio), encontram-se em um grupo diferente das outras duas amostras do Capibaribe.

As amostras de um mesmo rio quando localizadas em municípios/cidades distintas podem estar sofrendo ações antrópicas diferentes em cada local, por isso divergindo nos resultados apresentados. Quanto mais próximos os locais de coleta mais similaridades compartilham entre os descritores.

Com o objetivo de verificar qual o grau de relacionamento entre os coeficientes de similaridade, foram calculados os coeficientes de correlação linear de Pearson $(r)$. O coeficiente de correlação cofenética, (Fig. 13), pode ser utilizado para avaliar a consistência do padrão de agrupamento, sendo que valores próximos à unidade indicam melhor representação (Cruz e Carneiro, 2003).

O coeficiente de correlação cofenética é a correlação linear de Pearson entre os elementos da matriz de dissimilaridade e os elementos da matriz cofenética, ou seja, o coeficiente de correlação de Pearson avalia se há relação linear entre as variáveis. (Cargnelutti Filho et al., 2010).

A análise de correlação cofenética foi utilizada para somar a confiabilidade das conclusões frente à interpretação do dendrograma.

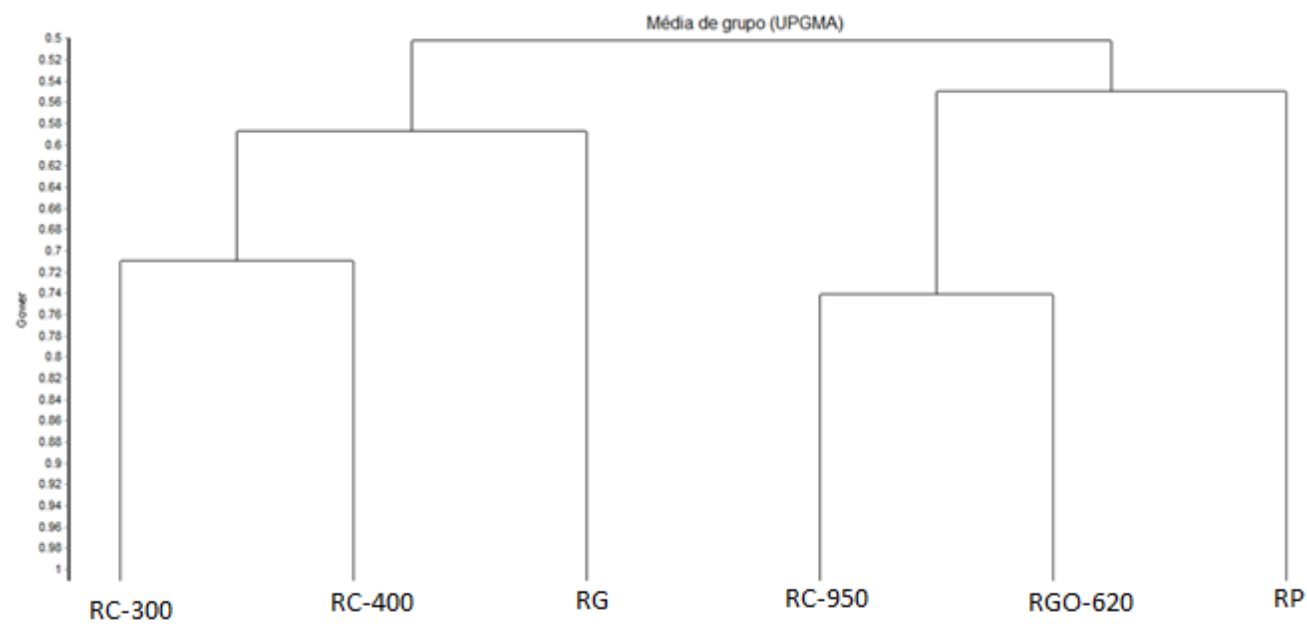

Figura 12: Dendograma gerado pela média do grupo (UGPMA) gerado pela relação das amostras e descritores utilizados na multivariada, sendo evidenciado a formação de dois grupos. 


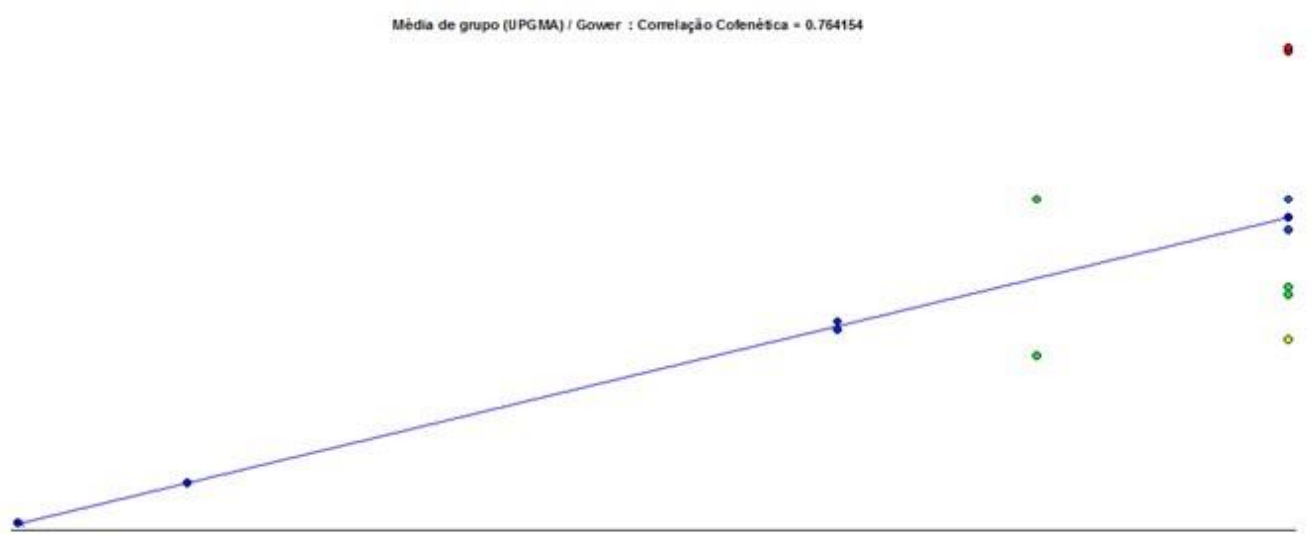

Figura 13: Correlação cofenética por média de grupo (UPGMA) do dendograma apresentando distância entre as amostras pelo índice de Gower.

O coeficiente de correlação de Pearson, mede essa tendência linear entre os coeficientes, assim, quanto mais próxima de 1 , menor será a distorção provocada pelo agrupamento das amostras com o método UPGMA (Fig. 13). O valor de correlação cofenética das amostras foi um pouco distante de 1 , com o valor de aproximadamente 0,76 , sendo ainda considerado satisfatório.

Quanto maior o coeficiente melhor o agrupamento e um coeficiente menor que 0,7 indica inadequação do método (Kopp et al., 2007). Portanto, deixa evidente que as amostras não são linearmente tão relacionadas entre si, confirmando com o resultado apresentado no dendograma (Fig. 12), onde as amostras são divididas em dois grandes grupos distintos (Meyer, 2002). Na matriz triangular, podemos observar através das cores a similaridade das amostras de acordo com os descritores utilizados (Fig. 14). Os tons avermelhados descrevem as amostras que possuem mais similaridades entre si e os tons azulados as que possuem uma menor similaridade.

A matriz apresentada (Fig. 14) corrobora com os resultados expressos no Dendograma da figura 13 e no Gráfico da Correlação Cofonética da figura 14, em que as amostras são agrupadas em dois grandes grupos. Onde, o RC-300 e RC-400 apresentam mais similaridades entre si de acordo com as cores mais quentes e no outro grupo as amostras que apresentam mais similaridades entre si em relação a sua composição físico-química são o RC-950 e RGO-620 destacado pela cor vermelha. Podemos notar na matriz que as cores em azul significam menor grau de similaridade entre si, mostrando que a amostra RC-950 e RGO-620 não possuem similaridade com a amostra RG, corroborando com o resultado expresso no dendograma (Fig. 12) em que eles são agrupados em grupos distintos. A análise de componente principal (PCA) é uma ferramenta de compreensão, utilizada com o objetivo de reduzir a dimensionalidade de um conjunto de dados e detectar variáveis mais significativas com o mínimo de perda dos dados originais, preservando o máximo de informação possível (Carvalho et al., 2015).

Girão et al. (2007), na seleção de indicadores de qualidade da água no rio Jaibaras utilizando-se a análise de componentes principais, verificaram que o primeiro, o segundo e o terceiro componente principal para um ponto de coleta em análise, explicaram, respectivamente, $37,57 \%, 30,87 \%$ e $11,57 \%$ da variância total dos dados, concentrando em três dimensões 80,19\% das informações.

Jianqin et al. (2010) utilizaram 14 tipos de indicadores de qualidade de água tais como sólidos suspensos, DQO, DBO, coliforme fecal, fósforo total, nitrogênio total, dentre outros, na avaliação de um modelo de qualidade de água baseado em análise de componentes principais. Os mesmos autores tiveram como resultado os três primeiros componentes principais respondendo por aproximadamente $65,8 \%$ da variação dos dados. Estes dados demonstram a funcionalidade da ferramenta de PCA no contexto da hidrologia ambiental especificamente na análise de qualidade de água.

Os indicadores analisados no presente estudo foram: $\mathrm{pH}$, oxigênio dissolvido (OD), temperatura, condutividade elétrica, turbidez, temperatura, nitrato, cor, fosfato total, DBO, 
nitrogênio amoniacal. Com a análise de componente principal (PCA) podemos observar quais os descritores que fizeram a separação das amostras em grupos, o tamanho da seta mostra a influência dos descritores nas amostras. O eixo da correlação/centrada da PCA que apresentou uma maior resposta para os eixos PC1 e PC2 foi o biplot 1:2, exibindo: $\mathrm{PC} 1(39.38 \%)$ e $\mathrm{PC} 2(21.80 \%)$, concentrando em duas dimensões $61,18 \%$ das informações (Fig. 15).

Diante disto podemos perceber que os descritores que influenciaram nas amostras da análise multivariada, respectivamente, foram: para o rio Gurjaú (RG) o que mais caracterizou foi o quantitativo de cor; para o rio Pirapama (RP) a concentração de nitrogênio amoniacal; para o rio Glória do Goitá (RGO-620) foi à concentração de fosfato total e temperatura; para o rio Capibaribe (RC-950) os descritores que caracterizaram foram condutividade, nitrato e DBO; para o RC-300 e RC-400 ambos do rio Capibaribe o quantitativo das variáveis físico-químicas apresentados foram próximos, o que gerou um agrupamento dessas amostras de acordo com a análise utilizada, além disto, essas amostras ficaram próximas dos descritores de $\mathrm{pH}$ e turbidez, no entanto, não foram suficientes para caracterizá-las dentro desses parâmetros (Fig. 15).

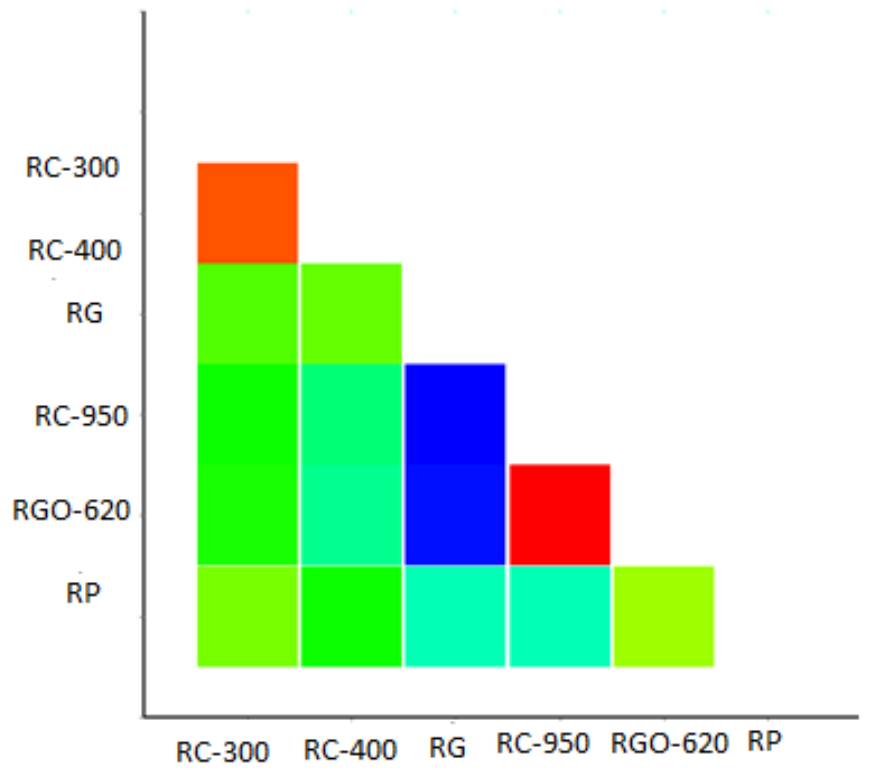

Figura 14: Matriz triangular das amostras e dos descritores utilizados para a multivariada. As variações de cores apresentam o teor de similaridade entre os resultados das amostras.

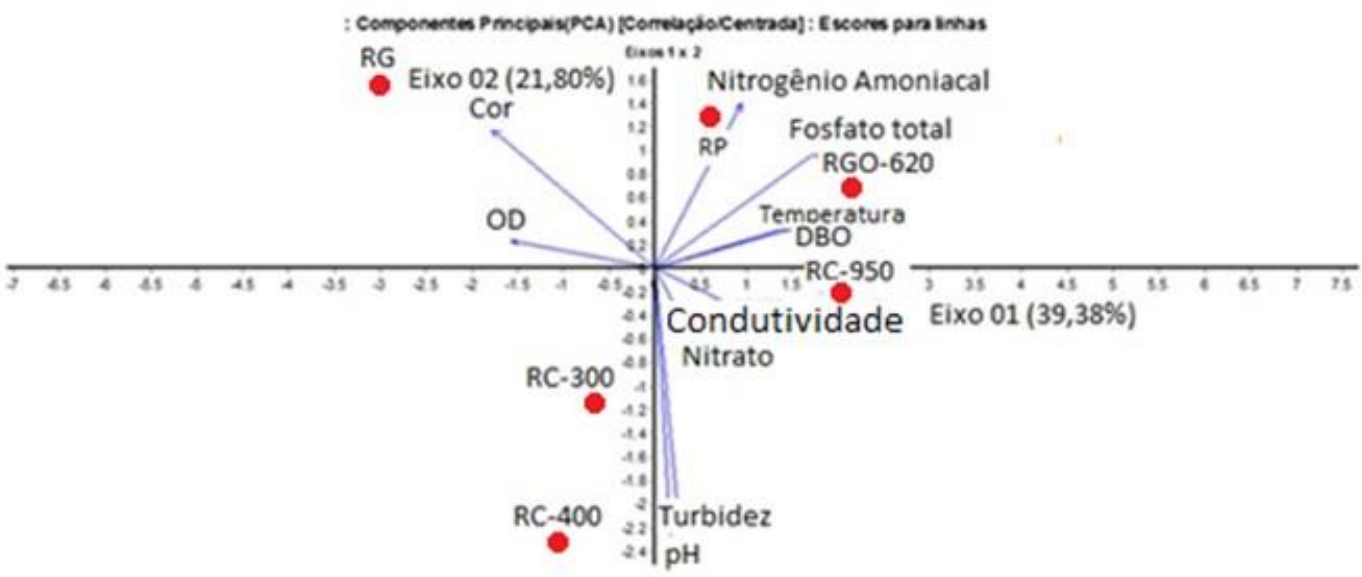

Figura 15: Análise de Componente Principal (PCA) entre as amostras RG, RP, RC-300, RC-400, RC-950 e RGO-620 e as variáveis físico-químicas da água. Sendo, os símbolos vermelhos as amostras e as setas os descritores. 
Através da matriz retangular (Fig. 16), também podemos observar a influência do quantitativo das amostras com os descritores, seguindo o mesmo padrão das cores da matriz triangular. As cores variam de acordo com a semelhança entre o quantitativo utilizado nas variáveis físico-químicas, sendo o tom mais vermelho as variáveis que possuem maior similaridade com as amostras e os tons azuis, as amostras que possuem menor similaridade em relação ao parâmetro descrito.

Os resultados expressos na matriz retangular (Fig. 16) corroboram com os resultados obtidos no gráfico da Análise de Componente Principal (PCA), onde os descritores caracterizaram as amostras dos rios com base na sua composição físico-química. As amostras de
RC-300 e RC-400 se caracterizaram pela concentração de pH, sendo a RC-300 também caracterizada pelo Oxigênio Dissolvido (OD) da amostra; já a amostra RG foi mais caracterizada pela cor (Fig. 15 e Fig. 16). Fazendo parte do outro grande grupo temos: a amostra RC-950 a qual foi caracterizada pela Condutividade e DBO; a amostra RGO-620, sendo caracterizada pela concentração de fosfato total e pela temperatura; e a amostra RP sendo caracterizada pela concentração de nitrogênio amoniacal e concentração de nitrato.

A maioria dos resultados observados na matriz corrobora com os resultados apresentados na PCA, ou seja, essas duas análises multivariadas podem ser utilizadas em conjunto para confirmação dos resultados propostos.

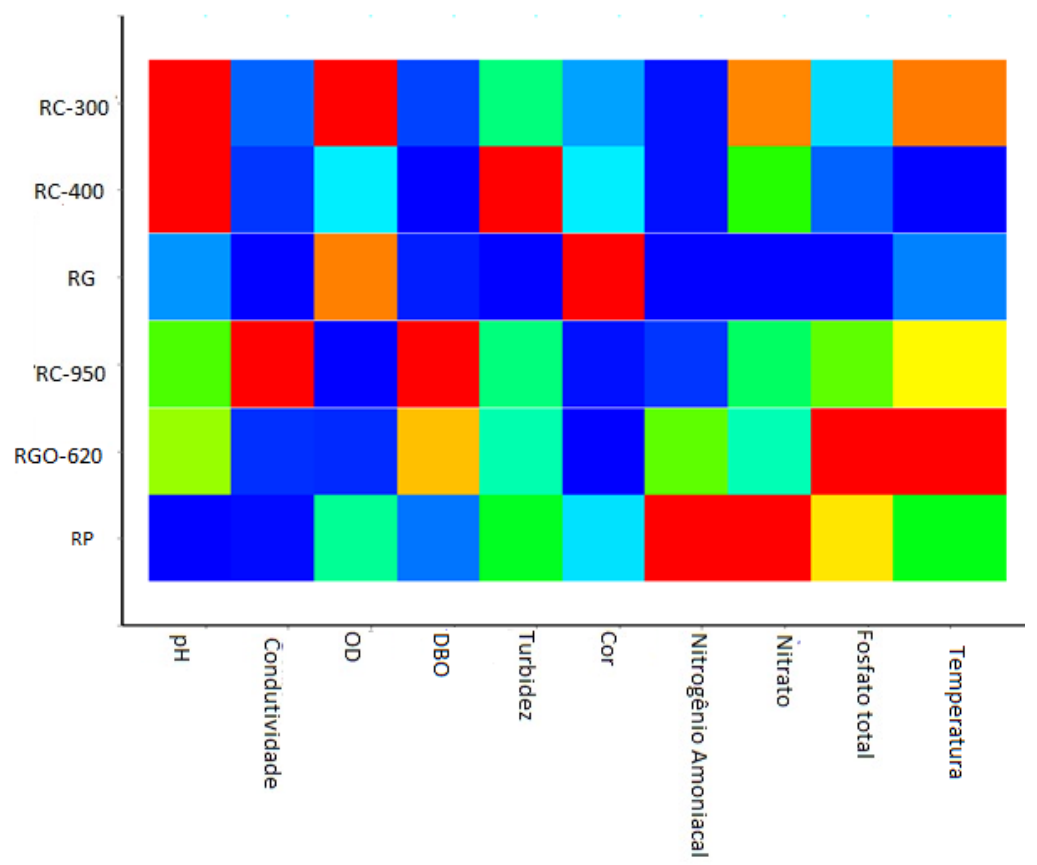

Figura 16: Matriz retangular mostrando a similaridade das amostras e dos descritores utilizados. A cor vermelha significa maior correlação da amostra com a variável e a cor azul menos correlação.

\section{Conclusão}

Os resultados das variáveis físico-químicas da água mostraram que as amostras de águas dos rios se apresentaram com algum dos parâmetros estudados alterado. Parâmetros como pH, cor, turbidez e nitrato se encontram dentro dos limites permitidos pela Resolução 357/05 do CONAMA para Águas se apresentaram com valores superiores aos permitido.
Em resumo, a análise conjunta evidenciouse que a amostra do rio Pirapama apresentou menor alteração em relação a análise físico-química quando comparados as outras amostras, tendo apenas o conteúdo de cor e nitrogênio amoniacal alterado possuindo um menor grau de degradação. As amostras dos rios Glória do Goitá-620 e do Capibaribe-950 apresentaram-se mais degradadas com alta taxa de DBO, que tem como consequência a eutrofização. Essas alterações também podem ser 
justificadas por estarem localizados mais próximos a áreas urbanas e não possuírem ETA ou possível inexistência de mata ciliar associada aos rios.

A análise multivariada conseguiu separar em dois grupos as amostras, sendo: RG, $\mathrm{RC}-300 \mathrm{e}$ RC-400; e RP, RGO-620 e RC-950. O grupo RG, RC-300 e RC-400 em sua totalidade apresentaram os resultados com maior conformidade com a resolução CONAMA 357/2005 do que o grupo com as amostras RP, RGO-620 e RC-950, ou seja, a análise conseguiu distinguir os grupos que apresentaram maiores alterações com a resolução vigente.

Dentre os parâmetros analisados os que mais impactaram na qualidade de água foram: condutividade elétrica, DBO, nitrogênio amoniacal e o fósforo total.

Por fim, os resultados demonstram que se faz importante o contínuo monitoramento das águas dos rios pernambucanos para verificar as alterações no curso hídrico, principalmente pelas ações humanas, que possam implicar para o uso da água pela sociedade.

\section{Agradecimentos}

Agradecemos à CPRH, COMPESA e Lógica Ambiental LTDA pelo fornecimento das análises físico-químicas para este estudo.

\section{Referências}

Agencia Estadual de Meio Ambiente - CPRH, 2013. Áreas Estuarinas. Disponível: http://www.cprh.pe.gov.br/perfis_ambientais/a reas_estuarinas/principais_problemas/39751\% 3B34671\%3B180204\%3B0\%3B0.asp. Acesso: 25 set. 2017.

Aguilera, P.A., Castro, H., Rescia, A., Schmitz, M.F., 2001. Methodological development of na index of coastal water quality: application in a tourist area. Environmental Management 27, 295-301.

Andrade, M.C., 2009. Geografia de Pernambuco: ambiente e sociedade, 1 ed. Editora Grafset, João Pessoa - PB.

Andrade, T.A., 1989. Métodos estatísticos e econométricos aplicados à análise regional, in: Haddad, P.R., Ferreira, C.M.C., Boisier, S., Andrade, T.A. (Ed). Economia regional: teorias e métodos de análise. 1 ed. BNB-ETENE, Fortaleza, pp.427-507.
APHA. American Public Health of Water and Wastewater, 1992. Standard methods for the examination of water and wastewater, 18 ed. American Public Health Association, Washington.

Barros, C.N., 2009. Coliformes na água e no molusco bivalve Anomalocardia brasiliana (Gmelin,1791) da Bacia do Pina, Recife - PE. IX Jornada de ensino, pesquisa e extensão da UFRPE, Universidade Federal Rural de Pernambuco. Anais. Recife: JEPEX [online] 16. Disponível:

http://www.eventosufrpe.com.br/jepex2009/cd/ resumos/r1115-2.pdf. Acesso: 10 nov. 2017.

Brasil - CONAMA, 2005. Resolução n. ${ }^{\circ}$ 357, de 17 de março de 2005. Diário Oficial da República Federativa do Brasil. Brasília. Disponível: http://www.mma.gov.br/port/conama/res/res05 /res35705.pdf. Acesso: 15 set. 2017

Brito, L.T.L., 2003. Avaliação de impactos das atividades antrópicas sobre os recursos hídricos da bacia hidrográfica do Rio Salitre-Bahia e classificação das fontes hídricas. Tese (Doutorado). Campina Grande, UFCG.

Brito, L.T.L., Silva, A.S., Srinivasan, V.S., Galvão, C.O., Gheyi, H.R., 2006. Uso de análise multivariada na classificação das fontes hídricas subterrâneas da bacia hidrográfica do Salitre. Engenharia Agrícola 26, 36-44.

Cargnelutti Filho, A., Ribeiro, N. D., Burin, C., 2010. Consistência do padrão de agrupamento de cultivares de feijão conforme medidas de dissimilaridade e métodos de agrupamento. Pesquisa Agropecuária Brasileira 45, 236-243. http://dx.doi.org/10.1590/S0100204X2010000300002.

Carvalho, F.I.M., Lemos, V.P., Dantas Filho, H. A., Dantas, K.G.F., 2015. Avaliação da qualidade das águas subterrâneas de Belém a partir de parâmetros físico-químicos e níveis de elementos traço usando análise multivariada. Revista Virtual de Química 7, 2221-2241. http://dx.doi.org/10.5935/19846835.20150132.

Ceballos, B.S.O., 1995. Utilização de indicadores microbiológicos na tipologia de ecossistemas aquáticos do Trópico Semi-Árido. Tese (Doutorado). São Paulo, USP.

Cornationi, M.B., 2010. Análises físico-químicas da água de abastecimento do município de colina - Bebedouro/ SP. Trabalho de Conclusão de Curso (Ciências Biológicas). Colina, Faculdades Integradas Fafibe. 
Cruz, C.D., Carneiro, P.C.S., 2003. Modelos biométricos aplicados ao melhoramento genético, 2 ed. Editora UFV, Viçosa.

Donadio, N.M.M., Galbiatti, J.A., Paula, R.C., 2005. Qualidade da Água de Nascentes com Diferentes Usos do Solo na Bacia Hidrográfica do Córrego Rico. Engenharia Agrícola 25, 115125.

Esteves, F.A., 2011. Fundamentos de Limnologia. 3 ed. Interciência/FINEP, Rio de Janeiro.

Ferreira, G.L.B.V., Ferreira, N.B.V., 2006. Fundamentos da Política Nacional de Recursos Hídricos. XIII SIMPEP [online] 13. Disponível: http://www.simpep.feb.unesp.br/anais/anais_1 3/artigos/810.pdf. Acesso: 10 nov. 2017.

Girão, E.G., Andrade, E.M., Rosa, M.F., Araújo, L.F.P., Meireles, A.C.M., 2007. Seleção dos indicadores da qualidade de água no Rio Jaibaras pelo emprego da análise da componente principal. Revista Ciência Agronômica 38, 17-24.

Jianqin, M., Jingjing, G., Xiaojie, L., 2010. Water quality model based on principal componente analisys and information entropy: application in Jinshui River. Journal of Resources and Ecology 3, 249-252. http://dx.doi.org/10.3969/j.issn.1674764x.2010.03.008.

Junior, J.F.H., Black, W.C., Babin, B.J., Anderson, R.E., Tatham, R.L., 2009. Análise Multivariada de dados, 6 ed. Editora Bookman, Porto Alegre.

Kopp, M.M., Souza, V.Q., Coimbra, J.L.M., Luz, V.K., Marini, N., Oliveira, A. C., 2007. Melhoria da correlação cofenética pela exclusão de unidades experimentais na construção de dendogramas. Revista da Fazva 14, 46-53.

Lordelo, L.M.K., Borja, P.C., Porsani, M.J., Andrade, J., Moraes, L.R.S., 2016. Qualidade das águas superficiais e subterrâneas do município de Santa Brígida - sertão da Bahia, para abastecimento humano. IV Congresso Baiano de Engenharia Sanitária e Ambiental [online] 4.4 Disponível: http://cobesa.com.br/2016/download/cobesa2016/IVCOBESA-047.pdf. Acesso: 20 nov. 2017.

Manly, B.F.J., 2008. Métodos estatísticos variados: uma introdução, 3 ed. Artmed, Wyoming U.S.A.

Medeiros, S.R.M., Carvalho, R.G., Souza, L.Di, Barbosa, A.H.S., 2016. Índice de qualidade das águas e balneabilidade no Riacho da Bica, Portalegre, RN, Brasil. Revista Ambiente e Água [online] 11, 711-730. http://dx.doi.org/10.4136/ambi-agua.1833.
Melo, A.S.R., Silva, C.B., Neto, M.V.B., Araújo, M.S.B., 2011. Estimativa da vulnerabilidade à erosão hídrica da bacia do Rio Goitá-PE, utilizando técnicas de Geoprocessamento e Sensoriamento Remoto. Anais XV Simpósio Brasileiro de Sensoriamento Remoto - SBSR [online] $15 . \quad$ Disponível: http://www.dsr.inpe.br/sbsr2011/files/p1394.pd f. Acesso: 10 nov. 2017.

Merten, G.H., Minella, J.P., 2002. Qualidade da água em bacias hidrográficas rurais: um desafio atual para a sobrevivência futura. Agroecologia e Desenvolvimento Rural Sustentável 3, 33-38. Disponível:

<http://taquari.emater.tche.br/docs/agroeco/rev ista/ano3_n4/artigo2. pdf >. Acesso em: 10 set. 2017.

Meyer, A.S., 2002. Comparação de coeficientes de similaridade usados em análises de agrupamento com dados de marcadores moleculares dominantes. Dissertação (Mestrado). São Paulo, USP.

Moita Neto, J.M., Moita, G.C., 1998. Uma introdução à análise exploratória de dados multivariados. Química Nova [online] 21. Disponível: http://dx.doi.org/10.1590/S010040421998000400016. Acesso: 11 out. 2017.

Nóbrega, A.S.C., 2011. Fontes de contaminação no estuário do Rio Capibaribe, Pernambuco. Trabalho de Conclusão de Curso (Bacharelado em Ciências Biológicas com ênfase em Ciências Ambientais) - UFPE.

Noriega, C.E.D., 2010. Estado trófico e balanço biogeoquímico dos nutrientes não conservativos ( $\mathrm{N}$ e $\mathrm{P}$ ), na região Metropolitana do Recife - Brasil. Tese (Doutorado). Recife, UFPE.

Parron, L.M., Muniz, D.H.F., Pereira, C.M., 2011. Manual de procedimentos de amostragem e análise físico-química de água, 1 ed. Embrapa Florestas, Colombo.

Philippi, J.A., Pelicioni, M., 2005. Educação Ambiental e Sustentabilidade, 2 ed. Editora Manole, Barueri.

Richter, C.A., Netto, J.M., 1999. Tratamento de água: Tecnologia atualizada, 2 ed. Editora Edgar Blucher Ltda, São Paulo.

Santiago, M.F., Cunha, M.G.G.S., Leitão, S.N., Costa, K.M.P., Palmeira, G.C.B., Porto Neto, F.F., Nunes, F.S., 2010. Phytoplankton dynamics in a highly eutrophic estuary in tropical Brazil. Brazilian Journal of oceanography 58, 189-205.

Schäfer, A., 1985. Fundamentos de Ecologia e Biogeografia das Águas Continentais, 2 ed. 
Editora da Universidade - UFRGS, Porto Alegre.

Silva, A.S., 1997. Impacto ambiental del uso de los recursos suelo y agua en áreas agrícolas bajo riego: estudio aplicado a zonas áridas brasileñas y españolas. Tese (Doutorado). Madrid, Universidad Politécnica de Madrid.

Silva, E.L., Cortez, D.A.G., Gonçalves, J. E., 2012. Estudo físico-químico e microbiológico do potencial impactante do efluente de abatedouros avícola e bovino. VI Mostra interna de trabalhos de Iniciação Cientifica [online] 6. Disponível:

https://www.unicesumar.edu.br/mostra2012/wp-

content/uploads/sites/93/2016/07/eduardo_lacc hi_silva.pdf. Acesso: 10 nov. 2017.
Tabarelli, M., Siqueira Filho, J.A., Santos, A.M.M., 2006. A floresta atlântica ao norte do Rio São Francisco, in: Pôrto, K.C., AlmeidaCortez, J.S., Tabarelli, M. (Org.), Diversidade biológica e conservação da floresta atlântica ao norte do rio São Francisco. Ministério do Meio Ambiente, Brasília, pp. 23-37.

Teixeira, S.F., Andrade, A.L.R.H., Campos, S.S., 2015. Qualidade da água no baixo rio Capibaribe, Recife, Pernambuco. $8^{\circ}$ Encontro de Internacional das Águas [online] 6. Disponível:

http://www.unicap.br/encontrodasaguas/wpcontent/uploads/2013/06/Simone-FerreiraTeixeira1-upe-Trabalho_2073004853.pdf. Acesso: 18 nov. 2017. 